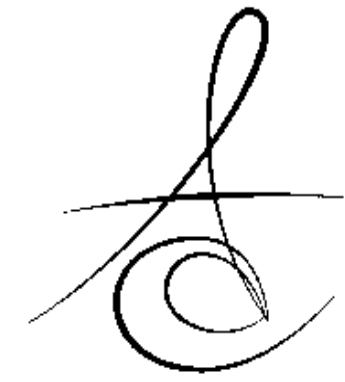

Makale Kodu/Article code: 2260

Makale Gönderilme tarihi; 27.04.2015

Kabul Tarihi: 02.06.2015

\section{DİŞ HEKİMLİĞİNDE KİTİN VE KİTOZAN}

\section{CHITIN AND CHITOSAN IN DENTISTRY}

\author{
Doç. Dr. Perihan OYAR*
}

\section{öz}

Kitozan kitinin deaset- ilasyonunundan oluşan bir polisakkarittir. Doğada bol miktarda bulur ve böceklerin kabuklarından elde edilir. Kitozan biyouyum ve anti-bakteriyal özelliklere sahip olduğundan dolayı biyomedikal uygulamalar için uygun bir fonksiyonel materyal olarak düşünülür. Polisakkaritler yüksek molekül ağırlığına sahip kondenzasyon polimerleridir. Polisakkaritler canlı organizmalarda birçok farklı görev gören doğal olarak oluşan biyomoleküllerdir. Kemik doku mühendisliği için test edilmiş ve alveolar doku rejenerasyonunda kullanım için pek çok mükemmel özelliklere sahip olduğu gösterilmiştir. Doğal polimerler arasında, kitozanın diş hekimliğinde uygulamaları geniş bir şekilde araştırılmaya devam etmektedir.

Anahtar kelimeler: Kitozan, kitin, biyomateryal

\section{ABSTRACT}

Chitosan is a polysaccharide derived from deacetylation of chitin. Chitin constitutes the exoskeletons of insects and crustaceans. Chitosan is considered as an appropriate functional material for biomedical applications because of its high biocompatibility and antibacterial properties. The polysaccharide is a condensation polymer with a high molecular weight. The polysaccharide is a biomoleculars which are formed by naturally and has many different function in living organism. Chitosan has been investigated for alveolar bone tissue engineering, indicating that the material has the potential and perfect property for alveolar bone regeneration applications. Among the natural polymers, chitosan has been widely studied for applications in dentistry.

Key words: Chitosan, chitin, biomaterial
Kitin yunanca kiton kelimesinden türetilmiştir ve zırh anlamına gelir. İlk olarak 1811 yılında mantarlarda keşfedilmiş, 1830 lu yıllarda böceklerden izole edilmiş ve 1859 yılında C. Rouget kitozanı keşfetmiştir. ${ }^{1-5}$ Kitin (2-asetamid-2-deoksi- $\beta$-D-glukoz) doğada yaygın bulunan bir biyopolimerdir ve selüloza benzer yapıdadır. Deniz eklem bacaklılarının dış iskeletlerinde, böceklerin epidermisleri ve mantarların hücre duvarlarında bulunur. ${ }^{1,4-8}$ Kitin bir çok organik çözücüde ve suda çözünmeyen hidrofobik bir polisakkarittir. ${ }^{1}$ Kitozan, kitinin deasetilzasyonu ile elde edilen polikatyonik bir polimerdir. ${ }^{1,4,5,7,8}$ Pozitif iyon yüküne sahip doğal bir polisakkarittir ve bu yüzden proteinler, anyonik polisakkaritler ve nükleik asitler gibi negatif yüklü moleküllerle etkileşime girebilirler. $^{9}$ Kitozan asetik asit, formik asit gibi dilue asitlerde çözülebilir deasetile bir kitindir.
Kitozan asidik çözeltilerde tam, zayıf alkalin çözeltilerde ise kısmen çözünür. ${ }^{1}$ Kitozanın elde edildiği kaynağın farklıı̆ına göre özellikleri değişir ve maddenin tüm özelliklerine yansır. Kitinin elde edildiği kaynağa göre 3 değişik kristal formu ( $a-, \beta-, \gamma^{-}$) bulunmaktadır. En çok a- formu kullanılmaktadır ve kolay elde edilebilir olmasından dolayı kitozanda çoğunlukla a- kitinden hazırlanmaktadır. $\beta$ - kitin, akitine göre çözücülere daha hassastır, yüksek reaktiviteye ve zayıf molekül içi kuvvetlere sahiptir. Kitozan kitinden daha reaktif bir materyaldir, bu özelliği jel, toz, fiber, film gibi değişik formlarda elde edilmesine imkan sağlamaktadır. ${ }^{1,6,10}$

\section{Kimyasal ve fiziksel özellikleri}

Kitozan, kitinin deasetilizasyonundan elde edilir. ${ }^{7,11}$ Kitin asetile edilirken, kitozan deasetile edilir. Bu yüzden kitin, asit çözeltilerinde vesuda çözünmez.

\footnotetext{
* Hacettepe Üniversitesi ,Sağlık Hizmetleri Meslek Yüksekokulu, Diş Protez Teknolojisi Proğramı
} 
Kitozan ise suda göreceli olarak, asidik çözeltilerde tam olarak çözünür. ${ }^{10}$ Kitin ve kitozan heteropolimer bir yapıya sahiptir ve selüloza göre yüksek oranda nitrojen içermesi kitin ve kitozanı metaller ile bileşik oluşturabilmede iyi bir kelasyon ( bazı metalik elementlerin ve minerallerin vücutta oluşan toksik etkilerini gidermede kullanılan bir yöntem) maddesi yapmaktadır. ${ }^{2}$ Kitozana göre kitin daha yüksek molekül ağırlığına sahiptir. Kitinin kitozana çevrilmesi ile molekül ağırlığı azalır ve deasitilizasyon derecesinin değişimine yol açar. $^{2}$ Kitozanın sudaki çözünürlüğünü kısmen deasitile edilmiş kitozanın molekül ağırlığındaki azalma ile artmaktadır. ${ }^{12}$ Kitozan stabil ve kristalin yapıdadır ve bundan dolayı normal olarak sulu çözeltilerde $\mathrm{pH} 7$ nin altında iken çözünmez... ${ }^{2,13,14}$ Kitin ve kitozanın fonksiyonelliğinin ortaya çıkarılabilmesi için uygun bir çözücü sistemde çözünmelidir. ${ }^{2}$ Kitin ve kitozanın in vivo ortamda parçalanması, bu materyallerin lizozomların neden olduğu enzimatik hidrolize duyarlılıklarından kaynaklanmaktadır. ${ }^{2,15}$ Kitin ve kitozan düşük toksisiteye sahiptir ve alerjik etki göstermeyen sağıklı ve enfeksiyonlu insan derisi için biyolojik olarak uyumlu bir materyal olduğu bildirilmiştir. ${ }^{1}$ Bazı kitozan tiplerinin antimikrobiyal ve bakteriostatik potansiyele sahip olduğu ve bunların hücre duvarına saldırarak mikrobiyal aktiviteyi inhibe ettiği gösterilmiştir. Mikroorganizmaların anyonik gruplarına kitozanın katyonik amino grupları bağlanıp bakterilerin büyümelerini ve gelişmelerini inhibe eder. ${ }^{2,10,16}$ İyileşmenin başlamasında kanamanın kontrol altına alınması önemlidir. Hemostazda yani kanama kontrolünün sağlanmasında kitozan etkili bir materyaldir. Bununla birlikte kitozan ve kitozan içerikli sütürler tıpta oldukça önemli bir yeniliktir. ${ }^{17-22}$

\section{Kitozanın yara iyileşmesine etkisi}

Kitozanın makro molekülleri hücre proliferasyonunu destekleyerek bağ doku organizasyonunu hızlandırır. Kitozan cerrahi yaralarda iyileşmeyi hızlandırır ve daha az skar oluşumuna sebep olup yara iyileşmesine katkıda bulunur. ${ }^{3,23,24}$ Yara iyileşmesini ve kapanmasını hızlandırmak amacı ile kitozan filmleri, süspansiyonları, çözeltileri, hidrojelleri ve yara örtüleri hazırlanmaktadır. ${ }^{15}$ Kitozanın yara tedavisinde kullanılabilmesini sağlayan önemli özellikleri; yara iyileşmesini hızlandırması, hijyenik olmayan koşullarda dahi kullanılabilmesi, antibiyotik kullanımını gerektirmemesi ve operasyonları kolaylaştırmasıdır. ${ }^{25}$ Kitozanın yaralara uygulanmasından sonra, histolojik olarak ciddi polimorfonükleer hücre infiltrasyonu, yara alanında makrofaj göçü ve yabancı dev hücreler görüldüğü bildirilmiştir. ${ }^{26}$ Bu bulgular ile iyileşmenin erken evrelerinde kitozanın proinflamatuar ürünlerin üretimini ve salgılanma yeteneğini artırdığı gösterilmiştir. Yara iyileşmesini etkileyen büyüme faktörlerini makrofajlar sentezlerler. Kitozan asetilenmiş gruplarına bağı olarak makrofajları aktive eder ve makrofajlardan doku onarımını hızlandıran sitokinlerin üretiminin artmasına sebep olur. ${ }^{27}$ Daha fazla fibroblast çoğalması sonucunda bağ dokusunun yeniden oluşumu ekstrasellüler matriks sentezi ile gerçekleşir. Granülasyon dokusunun kollajen tabakası kitozan uygulanmasıyla artar. Kitozan ekstrasellüler matriks üretimini direkt veya indirekt olarak uyarır ve fibroblast çoğalmasını artırır ${ }^{26,27}$ Kollajen III ve ganülasyon miktarının artmış olduğu kitozan uygulamasını takiben görülmüştür. ${ }^{26}$ Patojenler ve tümör hücrelerine karşı immünolojik cevapta rol oynayan hücrelerin fonksiyonunu kitin ve kitozanın artırdığı, tümör hücrelerinin içine seçici olarak toplanıp tümör hücrelerinin büyümesini baskıladığı bildirilmiştir... ${ }^{2,15}$

\section{Kemik dokusu üzerinde kitozanın iyileştirici etkisi}

Kitinin parsiyal olarak deasetile edilmiş şekli olan kitozan, yara iyileşmesinde fibroplaziyi engelleyip, doku farkılışmasını, gelişimini ve yeniden yapılmasını sağlayan doğal bir polimerdir. ${ }^{28}$ Hidaka ve ark. ${ }^{29}$ sIçanların kafatasına kitozan ile hazırladıkları membranları subperiostal olarak implante etmişler ve \%65, 70 ve 80 deasetilize kitozan membranların granülasyon dokusu ve kemik oluşumunu gözlemişlerdir. Klokkevold ve ark. ${ }^{22,30}$ kitozanın hyaluronik asite benzer yapıya sahip olduğunu, kök hücre artışında, göçünde ve doku rejenerasyonunda teşvik edici olduğunu bildirmişlerdir. Ito ve ark. ${ }^{31}$ kitozan hidroksiapatit kemik dolgu materyalinin in vitro özelliklerini incelemişler ve kanselöz kemiğin sıkıştırabilme kuvvetine yakın bir kuvvete sahip olduğunu ve kemik defektlerinin doldurulmasında fayda sağlayabileceği belirtmişlerdir. Viala ve $a k^{32}$ oktakalsiyum fosfatın kristalizasyonunu kitozanın önemli ölçüde hızlandırdığını göstermişlerdir. Park ve ark, ${ }^{33,34}$ ve Lee ve ark. ${ }^{35}$ geliştirdikleri 3 boyutlu kitozan/ trikalsiyumfosfat yapının, osteoblast kültürü ortamında kemik oluşumuna etkisini inceledikleri çalışmalarında kitozan/ trikalsiyum fosfat matriksin osteoblastların kültür ortamında çoğaltılarak istenilen hedef sahaya transplante edilebileceği ve kemik rejenerasyonunda biyolojik olarak yıkılabilen bir matriks olarak fayda sağlanabileceğini belirtmişlerdir. 
Muzzarelli ve ark. ${ }^{3}$ kitozan askorbatı, insanlarda periodontal kemik defektlerine yerleşmişler ve diş mobilitesinin ve cep derinliğinin azaldığını bulmuşlardır. Muzaarelli ve ark. ${ }^{36}$ insanlarda 3. molar diş çekim boşluklarına ve apikal rezeksiyon sahalarına dondurulmuş kurutulmuş metilpirodilon kitozanı yerleştirmişler ve metilpirolidon kitozanın osteokondüktif etki göstererek, kemik boşluklarında, mekanik ve fizyolojik özelliklere sahip yeni kemik oluşumu sağladığını göstermişlerdir. Muzzarelli ve ark. ${ }^{37}$ tavşan tibialarında oluşturdukları defektlere dondurulmuş-kurutulmuş metilpirolidon kitozan yerleştirmişler ve yeni kemik oluşumu gerçekleştiğini bulmuşlardır. Araştırmacılara göre osteoprogenitör hücreler, kitozan-pıhtı karışımı içerisinde hapis olan büyüme faktörleri tarafından stimüle edilmişlerdir. Oliveira ve ark $^{38}$ kitozanın osteokondüktif özelliklere sahip olduğunu belirtmişlerdir. Farea ve ark. ${ }^{39}$ ve Peter ve ark. ${ }^{40}$ ise alveolar kemik rejenerasyonu uygulamaları açısından kitozanın bir potansiyele sahip olduğunu ifade etmişlerdir. Bhattarai ve ark ${ }^{41}$ titanyum implantların kullanımında osteoklastik aktiviteyi azalttığı ve osteogenezi arttırdığını bulmuşlardır.

\section{Yumuşak doku üzerine kitozanın iyileştirici etkisi}

Kitozanın yumuşak dokuda oluşan her türlü yaranın tedavisinde hem tek başına, hemde çok çeşitli biyoaktif maddelerle bir arada kullanıldığı uygulamalar mevcuttur. Pek çok çalışmada kitozanın deri, mukoza, sinir, kıkırdak, retina, ürogenital, periodontal, kas ve tendon yaralanmalarında iyileşmeyi hızlandırıcı etkileri olduğu belirlenmiştir. ${ }^{42-49}$ Kitozanla iyileşen yaralarda yeni oluşan kollagen miktarının fazla olduğu özellikle tip III kollagende artışlar olduğu görülmüş ve kitozanın granülasyon fazının gelişimine destek olduğu ifade edilmiştir. Dolaşımda bulunan monositler ile makrofajlar yara bölgesine göç ederlek yara iyileşmesinde etkili olacak olan büyüme faktörlerini sentezlerler. Glukan makrofaj aktivite edici bir ajandır ve makrofajlardan sitokin üretimini hızlandırır. Kitozan da glukan benzeri bir polisakkarittir ve sitokinlerin üretilmesinde rol oynar. ${ }^{26,27,50}$ Sail ve arkadaşları ${ }^{46}$ çinko oksit ile kito- san nanopartiküllerin kombinasyonu gibi katyonik antibakteriyel nanopartiküller ile tedavi edilen kök kanal yüzeyi üzerinde dentine yapışmış olan E. Faecalis'in sayısında azalma olduğunu bulmuşlardır.

\section{Kitozanın biyomedikal ve farmasötik uygulamaları}

Kitozanın, fizikokimyasal özellikleri, biyolojik ve kimyasal aktifliği, çok çeşitli formlarda elde edilebilirliği, diğer polimerler ile uyumu ve ekonomik olması bir çok biyomedikal uygulamada kullanılmasını sağlamıştır. ${ }^{5,7,10,151-53}$ Özellikle pomatlar içinde önemli oranda kitin-kitozan bulunmaktadır. ${ }^{54,55}$ Biyolojik maddelerin, proteinlerin ve peptid yapıdaki ilaçların taşınmasında kullanılır. Bu yöntem ilaç alım sıklığını azaltarak ve hastanın önerilen doz uygulamasına uyum sağlamasına yardımcı olur. ${ }^{2}$ Lokal ilaç taşıma sistemleri periodontal hastalıkların tedavisinde son zamanlarda önemli hale gelmiştir. ${ }^{56}$

Dental implant uygulamalarında antibiyotik taşıyıcı olarak kullanılması konusunda ümit vaad edici olduğu ${ }^{57-59}$, implantlarda erken dönemde oluşabilecek enfeksiyona engel olmak için etkili olduğu belirtilmiştir. $^{60}$ Çürük oluşumunu önlemek ve bakteriyal çoğalmayı azaltmak için oral hijyenin sağlanması amacıyla ağız gargaralarında kullanılabileceği belirtilmiştir. ${ }^{61,62}$ Tamir dentini oluşumunu sağladığı ve demineralizasyonu inhibe ettiği bulunmuştur. ${ }^{63,64}$

Kitozanın kullanıldığı başka bir ilaç taşıyıcı sistem hidrojellerdir. Hidrojeller hidofilik polimer ağlarıdır ve büyük miktarlarda su absorbe edip hacmi hızla artan yapılardır. Bu özellik yüksek miktarda ilaç taşınmasına ve salınımına olanak sağlar. ${ }^{1,2,65}$ Kitozanın kullanıldığı bir başka alan ise oftalmolojidir. Oküler ilaçların etkinliğini artırmada polimer esaslı hidrojeller kullanarak ilacın perikorneal alandaki bulunma süresi artırılmaktır. ${ }^{2,66}$ Kitozan kalp damar cerrahisinde, sütür materyallerinde ve yanık tedavisinde kullanılmaktadır. ${ }^{5,67,68}$ Kuru hava, İyonizasyon ışıması , doymuş buhar ve kimyasal ajanlar (etilen oksit, etanol vb) kitozanın sterilizasyon yöntemlerinde kullanıldığı diğer alan$\mathrm{dir}^{15,69}$.

\section{SONUÇ}

Gelecekte yeni dental materyaller, yeni teşhis ve tedavi teknikleri ve farmakolojik yaklaşımlar gelişecek ve doku mühendisliği ve biyoteknolojinin kullanıımasıyla çok önemli gelişmeler olacaktır. ${ }^{70}$ 


\section{KAYNAKLAR}

1. Dodane V, VilivalamVD. Pharmaceutical applications of citosan. PSTT 1 1998;6:246-53.

2. Shukla SK, Mishra AK, Arotiba OA, Mamba BB. Chitosan-based nanomaterials: a state-of-theart review. Int J Biol Macromol 2013;59:46-58.

3. Muzzarelli R, Biagini G, Pugnaloni A. Reconstruction of parodontal tissue with chitosan. Biomaterials 1989;10:598-603.

4. Shepherd R, Reader S, Falshaw A. Chitosan functional properties. Glycoconj J 1997;14:535-42.

5. Singh DK, Ray AR. Biomedical applications of chitin, chitosan, and their derivates. Rev Macromol Chem Phys 2000;40:69-83.

6. Gomez BC, Duncan R. Evaluation of the biological properties of soluble chitosan and chitosan microspheres. Int Jour Pharmaceutics 1997;148:231-40.

7. Akbuğa JA. Biopolymer. Chitosan. Int J Pharm Advances 1995;1:3-8.

8. Ottoy MH, Varum KM. Compositional heterogeneity of heterogeneous deacetylated chitosan. Carbohyd Polym 1996;29:17-24.

9. Lyoyd LL, Kennedya JF. Carbohydrate polymers as wound management aids. Carbohyd Polym 1998 37;315-22.

10. Koide SS. Chitin-Chitosan. properties, benefits and risks. Nutrition Research 1998;18:1091-101.

11. Asden T, Illum Skaugrud O. The effect of chronic nasalapplication of chitosan solutions on cilia beat frequency in guinea pigs. Int Jour Pharmaceutics 1997; 153:137-46.

12. Kubota N, Tatsumoto N, Sano T, Toya K. A simple preparation of half $\mathrm{N}$-acetylated chitosan highly souble in water and aqueous organic solvents. Carbohydr Res 2000;324:268-74.

13. Jaworska M, Sakurai K, Gaudon P, Guibal E. Influence of chitosan characteristics on polymer properties. Crystallographic properties. Polym Int 2003;52:198-205.

14. Suh JKF, Mattehew HWT. Application of chitosanbased polysaccharide biomaterials, in cartilage tissue engineerin. A review. Biomaterials 2000;21:2489-598.

15. Khor $\mathrm{E}$, Lim LY. Implantable applications of chitin and chitosan. Biomaterials 2003;24:2339-49.
16. Aimin C, Chunlin H, Juliang B. Antibiotic loated chitosan bar. An in vitro, in vivo study of a possible treatment for osteomyelitis. Clin Orthop Relat Res 1999;366:239-47.

17. Fukasawa M, Abe $H$, Masaoka T, Orrita $H$. The hemostatic effect of deacetylated chitin membrane on peritoneal Injury in rabbit model. Jpn J Surg 1992;22:333-8.

18. Hagiwara $K$, Kribayashi $Y$, Iwai $H$, Ishihara C. A sulfated chitin inhibits hemagglutination by Theileria Sergenti Merozoites. Carbohyd Polym 1999;39:245-8.

19. Hirano S, Zhang M, Nakagawa M, Miyata T. Wet spun chitosan-collagen fibers, their chemical $\mathrm{N}$ modifications, and blood compatibility. Biomaterials 2000;21:997-1003.

20. Ishihara C, Shimakawa S, Tsuji M. A sulfated chitin, SCM-chitin III, inhibits the clearence of human erytocytes from the blood circulation in eryrocyte-transfused SCID mice. Immunopharmacology 1995;29:65-71.

21. Klokkevold PR, Fukayama $H$. The effect of chitosan (poly-N-Acetyl Glucosamine) on lingual hemostasis in heparinized rabbits. J Oral Maxillofac Surg 1999;57:49-52.

22. Klokkevold PR, Lew DS. The effect of chitosan on lingual hemostasis in rabbits. J Oral Maxillofac Surg 1991;49:858-63.

23. Mori T, Okumura M, Matsuura M, Ueno K. Effect of chitin and its derivatives on the proliferation and cytokine production of fibroblasts in vitro. Biomaterials 1997;18:947-51.

24. Anitha A, Sowmya S, Sudheesh Kumar PT, Deepthi S, Chennazhi KP, Ehrlich H, Tsurkan M, Jayakumar R. Chitin and chitosan in selected biomedical application. Progress in Polymer Science 2014;39: 1644-67.

25. Shigemasa $Y$, Minami S. Applications of Chitin and Chitosan for biomaterials. Biotechnol Genet Eng Rev 1995;13:383-420.

26. Ueno $H$, Mori $T$, Fujinaga $T$. Topical formuşations and wound healing applications of chitosan. Adv Drug Deliv REv 2001;52:105-15.

27. Ueno H, Nakamura F, Murakami M, Okumura M, Kadosawa T, Fujinaga T. Evaluation effect of chitosan fort he extracellular matrix production by fibroblasts and the growth factors production by macrophages. Biomaterials 2001;22:2125-30. 
28. Muzzarelli R, Conti F, Ferara P. Biological activity of chitosan. Ultrastructural study. Biomaterials 1988;9:247-52.

29. Hidaka $Y$, Ito $M L$, Mori $K$, Yagasaki $H$. Histopathological and immunohistochemical studies of membranes of deacetylated chitin derivatives implanted over rat calvaria. J Biomed Mater Res 1999;46:418-23.

30. Klokkevold PR, Vandemark L, Kenney EB. Osteogenesis enhanced by chitosan (poly- $\mathrm{N}$-acetyl glucosaminoglycan) in vitro. J Periodontol 1996;67:1170-5.

31. Ito $M$, Yamagishi T, Yagasaki $H$. In vitro properties of chitosan-bonded bone-filling paste. Studies on solubility of calcium phosphate compounds. J Biomed Mater Res 1996;32:95-8.

32. Viala S, Freche M, Lacout LJ. Effect of chitosan on octacalcium phoshate crystal growth. Carbohyd Polym 1996;29:197-201.

33. Park YJ, Lee YM, Park SN. Platelet derived frowth factor releasing chitosan sponge for periodontalbone rejeneration. Biomaterials 2000;21:153-9.

34. Park YJ, Lee YM. Controlled release of plateletderived growth factor-BB fromchondroitin sulfatechitosan sponge for guided bone regeneration. J Control Release 2000;67:385-94.

35. Lee YM, Park YJ, Lee SJ. Tissue engineered bone formation using chitosan/tricalcium phoshate sponges. J Periodontol 2000;71:410-7.

36. Muzzarelli RAA, Biagini G, Bellardini M. Osteocunduction exerted by methylpyrolidinone chitosan used in dental surgery. Biomaterials 1993;14:39-43.

37. Muzzarelli RAA, Zucchini C, Ilaari P. Osteocunductive properties of methylpyrolidinone chitosan in animal model. Biomaterials 1993; 14:925-9.

38. Nuno Guitian Oliveira, Luís F.V. Pinto, Luís Reis, Alexandra Rodrigues. Competitiveness of chitosanbased implants. Ciência \& Tecnologia dos Materiais, Volume 2014;26:77-88.

39. Farea M, Husein A, Halim AS, Abdullah NA, Mokhtar KI, Lim CK, Berahim Z, Mokhtar K. Synergistic effects of chitosan scaffold and $\mathrm{TGF}_{1}$ on the proliferation and osteogenic differentiation of dental pulp stem cells derived from human exfoliated deciduous teeth. Arch Oral Biol 2014;59:1400-11.

40. M. Peter, NS Binulal, SV Nair, N Selvamurugan, $H$ Tamura, R. Jayakumar. Novel biodegradable chitosan- gelatin/nano bioactive glass ceramic composite scaffolds for alveolar bone tissue engineering. Chem Eng J 2010;158:353-61.

41. Bhattarai G, Lee $Y-H$, Lee $M-H$, Park S, Yi H-K . Insulin-like growth factor binding protein-3 affects osteogenic efficacy on dental implants in rat mandible. Materials Science and Engineering: C, 2015, basım aşamasında.

42. Bartone F, Adickers E. Chitosan. Effects on wound healing in urogenital t,ssue: preliminary report. J Urol 1988;140:1134-7.

43. Gérentes P, Vachoud L, Doury J, Domard A. Study of a chitin-based gel as injectable material in peridontal surgery. Biomaterials 2002;23:1295-302.

44. Gingrans M, Paradis I. Nevre regeneration in collagen-chitosan tissue-engineeringskintransplanted on nude mice. Biomaterials 2003;24:1653-61.

45. Okamoto $Y$, Southwood L, Stashak TS. Effect of chitin onnnnn nonwoven fabric implant in tendon healing. Carbohyd Polym 1997;33:33-8.

46. Sall K, kreter JK, Keates RH. The effect of chitosan on corneal wound healing. Ann Ophthalmol 1987; 19:31-3.

47. Taravel MN, Domard A. Collagen and itsinteraction with chitosan-II influence of the physicochemical characteristics ofcollagen. Biomaterials 1995;16:865-71.

48. Taraval MN, Domard A. Collagen and its interaction with chitosan-III. Some biological and mechanical properties. Biomaterials 1996;17:451-5.

49. Yeo HJ, Lee KG. The effect PVA/chitosan/fibroin (PCF)-blended spongy sheets on wound healing in rats. Biol Pharm Bull 2000;23:1220-3.

50. Oeno $H$, Yamada $H$, Tanaka I, Kaba N. Accelerating effects of chitosan for healing at early phase of experimental open wound in dogs. Biomaterials 1999;20:1404-14.

51. Kishen A, Shi Z, Shrestha A, Neoh KG. An investigation on the antibacterial and antibiofilm efficacy of cationic nanoparticulates for root canal infection. J Endod 2008; 34: 1515-20.

52. Chandra R, Rustgı R. Biodegradable polymers. Prog Polym Sci 1998;23:1273-335.

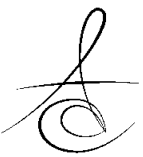


53. Cheng M, Deng J. Study on physical properties and nevre cell affinity of composite films from chisosan and gelatin solutions. Biomaterials 2003;24:287180.

54. Aral C, Akbuğa J. Alternative approach to the preparation of chitosan beads. Int J Pharm 1998;168:9-15.

55. Pereira F, Pereira C, Lacerda MH. Contact dermatitis due to a cream containing chitin and a carbitol. Contact Dermatitis 1998;38:290-1.

56. İkinci G, Şenel S, Akıncı H, Kaş S, Ercis S. Effect of chitosan on a periodontal pathogen porphyromonas gingivalis. Int J Pharm 2002;235:121-7.

57. Busilacchi, A., Gigante, A., Mattioli-Belmonte, M., Manzotti, S., \& Muzzarelli, R. A. A. Characterization and cytocompatibility of an antibiotic/ chitosan/ cyclodextrins nanocoating on titanium implants. Carbohydr Polym. Carbohydrate Polymers 2014; 110:173-82.

58. Anitha A, Sowmya S, Sudheesh PT, Kumar S. Deepthi, Chennazhi KP, Ehrlich $H$, Tsurkan M, Jayakumar R. Chitin and chitosan in selected biomedical applications. Prog Polym Sci 2014; 39 1644-67.

59. Ordikhani F, Simchi A. Long-term antibiotic delivery by chitosan-based composite coatingswith bone regenerative potential. Appl Surf Sci 2014;317: 5666.

60. Hongbin Lv, Chen Z, Yang X, Cen L, Xu Zhang, Gao $P$. Layer-by-layer self-assembly of minocyclineloaded chitosan/alginate multilayer on titanium substrates to inhibit biofilm formation. J Dent 2014; 42:1464-72.

61.Samprasit W, Kaomongkolgit R, Sukma M, Rojanarata T, Ngawhirunpat T, Opanasopit P. Mucoadhesive electrospun chitosan-based nanofibre mats for dental caries prevention. Carbohydr Polym 2015;117: 933-40.

62. Costa E M, S. Silva, AR. Madureira, A. CardelleCobas, F.K. Tavaria, M.M. Pintado. A comprehensive study into the impact of a chitosan mouthwash upon oral microorganism's biofilm formation in vitro. Carbohydr Polym 2014;101:1081-86.

63. Arnaud TM, de Barros Neto B, Diniz FB. Chitosan effect on dental enamel de-remineralization: $A n$ in vitro evaluation. J Dent 2010;38:848-52.
64. Li F, Liu X, Zhao S, Wu H, Xu HH. Porous chitosan bilayer membrane containing TGF- $\beta_{1}$ loaded microspheres for pulp capping and reparative dentin formation in a dog model. Dent Mater 2014;30:172-81.

65. Risbud MV, Hardikar AA, Bhat SV. pH-sensitive frezdried chitosan-polyvinyl pyrolidone hydrogels as controlled release system for antibiotic delivery. J Control Release 2000;68:23-30.

66. Felt O, Furrer $\mathrm{P}$, Mayer JM, Plazonnet B, Buri P. Topical use of chitosan in ophthalmology: tolerance assessment and evaluation of precorneal retention. Int J Pharm 1999;180:185-193.

67. Denuziere A, Ferrier D, Damour O, Domar A. Chitosan-chondrotin sulfate and chitosan-hyalunate polyelectrolyte complexes: biological properties. Biomaterials 1998;19:1275-85.

68. Shanthi C, Rao KP. Chitosan modified poly(glycidyl methacrylate-butylacrylate) copolymer grafted bovine pericardial tissue-anticalcificationproperties. Carbohyd Polym 2001;44:123-31.

69. Zahraouı C, Sharrock P. Influence of sterilization on injectable bone biomateriels Bone 1999;25:635.

70. Oyar P. Diş hekimliğinde nanopartiküllerin kullanım alanları. Atatürk Üniv Diş Hek Fak Derg 2014; Suppl:8:49-55.

\section{Yazışma Adresi}

Doç. Dr Perihan OYAR

Hacettepe Üniversitesi

Sağlık Hizmetleri Meslek Yüksekokulu, DişProtez Teknolojisi Programı,

D-Blok, 3. Kat, 06100 Sıhhıye-Ankara / TÜRKİYE, Fax: +90-312-3102730, telefon: +90-312-305 1587 / 111, e-mail: poyar73@gmail.com 